\title{
The Cooperation-Competition Model for the Hot Topics of Chinese Microblogs
}

\author{
Weiwei $\mathrm{Wu}$ \\ College of Information Engineering \\ AnHui XinHua University, \\ Hefei Anhui, China \\ e-mail: wuweiwei@mail.ustc.edu.cn
}

\begin{abstract}
The Chinese microblog (Weibo) grows quickly and eventually has been an essential tool for Chinese netizens. This paper proposes a cooperation-competition model for the trend of the hot issues of Sina Weibo based on some hypothesis and parameter settings. After using the equilibrium solution theory of differential equations to solve the cooperation-competition model, the appropriate strategies to control the trend of hot issues are stated.
\end{abstract}

Keywords-hot topics; cooperation-competition model; Sina Weibo; equilibrium solution theory

\section{INTRODUCTION}

The development of the Internet industry in China over the past decade has been impressive [1]. According to a survey from the China Internet Network Information Center (CNNIC), by July 2012, the number of Internet users in China has reached 538 million, as the world's largest Internet market [2].

There has been a tremendous rise in the growth of online social networks all over the world in recent times. Popular networks such as Facebook and Twitter are well-known globally and contain several hundreds of millions of users all over the world [3]. Sina Weibo is the most popular microblogging network in China, almost all of the users are located in China and post in the Chinese language [4, 5, 6 and 7]. According to the Sina corporation report of 2nd season of 2012, Sina Weibo now has more than 368 million users. About 100 million messages are posted everyday on Sina Weibo.

Sina Weibo users can post messages containing text, pictures, videos and links by both computers and mobile phones. At the same time, they can address “@” their messages and other interesting messages to their friends and other users, and can mention others in their messages. Sina Weibo also has the forward (retweet) function and commenting function. Based on the above reasons, the spread speed of the hot issues (messages) in Weibo is more quickly than the media formats, event than the classical social networks, for example, Bulletin Board System.

Sina Weibo has many trending topics everyday. Based on the use and importance to enhance the social construction of ideological infrastructure, the trending topics fall into several categories as "good", "bad" or "normal". As we know, it is the goal of Sina Weibo and other related departments that there are more good hot topics and less bad hot topics. The trend and the control for the hot issues is the main problem of this article. We will use a cooperation-competition model to describe the system based on some assumptions. The tool to solve the mathematic model is the equilibrium solution theory of differential equations [8, 9, 10 and 11].

The paper is organized as follows. The cooperationcompetition model is established in section 2. Based on the equilibrium solution theory of differential equations, the appropriate complete strategic classifications to control the trend of the hot topics are given in section 3. Section 4 is devoted to conclusions and discussions.

\section{MATHEMATIC ModeL}

According to the market share for the users of Sina Weibo, the hot topics are divided into three categories by simply as follows.

Site 1: the selected hot topics, i.e. good ones on the social value;

Site 2: the small site, i.e. normal hot topics, whose market share is smaller than an assumed value since they are less interesting than the bad ones;

Site 3: the powerful site, i.e. bad hot topics, generally they are more interesting than another ones to the Weibo users, and the market share is bigger than a given value.

\section{A. Assumption}

(1) The selected site 1 has chosen to cooperate with the small site and to compete with the powerful site, this assumption is reasonable and very important, and the reason will be further explained in section 3 ;

(2) The sum of the market share of three class hot issues should be more than 1 because of the special nature of the Internet: the users of Sina Weibo can be the customs of site 1 , 2 and 3 at the same time.

\section{B. Coopetition model}

Based on the above assumptions, the coopetition model will be constructed as follows.

$$
\left\{\begin{array}{l}
F_{1}^{\prime}=F_{1}\left(P_{1}+Q_{1}+R_{1}-P_{1} Y_{1} F_{1}-Q_{1} Y_{1} F_{1}-R_{1} Y_{1} F_{1}+X_{12} F_{2}-X_{13} F_{3}\right) \\
F_{2}^{\prime}=F_{2}\left(P_{2}+Q_{2}+R_{2}-P_{2} Y_{2} F_{2}-Q_{2} Y_{2} F_{2}-R_{2} Y_{2} F_{2}+X_{21} F_{1}-X_{23} F_{3}\right) \\
F_{3}^{\prime}=F_{3}\left(P_{3}+Q_{3}+R_{3}-P_{3} Y_{3} F_{3}-Q_{3} Y_{3} F_{3}-R_{3} Y_{3} F_{3}-X_{31} F_{1}-X_{32} F_{2}\right)
\end{array}\right.
$$

Variable $F_{n}$ is their market share for the site n. $F_{n}^{\prime}=d F_{n} / d t$ is the rate of change of the market share. $P_{n}$ is defined as the rate of self-development of site $n$ for $n=1,2,3$, it means the ratio of the hot issue's own customers from the original message. $Q_{n}$ measures the ratio of the customer 
from the subsequent messages about the new evolvement of the hot topics. $P_{n}, Q_{n}$ are the quality indicators of the messages of the hot issues. If one message can provide interesting pictures and use the excellent language, its $P_{n}$ and $Q_{n}$ will increase quickly. $R_{n}$ measures the ratio of the customers from the market cooperation-competition, for example, we can add introduce the hot issue 1 on the webpage of the hot issue 2. The notation $X_{12}\left(X_{12}>0\right)$ denotes the cooperation rate between site 1 and site 2 , which measures the fraction of customers that site 1 obtains because of site 2. Cooperation rate $X_{12}$ reflects both the degree of mutual cooperation between enterprises, $X_{12}$ is the bigger the better for the selected site. The first class site can improve the cooperation rate $X_{12}$. The notation $X_{21}\left(X_{21}>0\right)$ is defined similarly. $X_{13}\left(X_{13}>0\right)$ is the competition rate between sites 1 and 3 , which measures the fraction of customers that site 1 loses because of site 3 . Parameters $X_{23}, X_{31}, X_{32}$ are also positive and defined by the same way. The largest market share of the site $\mathrm{n}$ to achieve will be denoted as $1 / Y_{n}\left(Y_{n}>0\right)$.

The template is used to format your paper and style the text. All margins, column widths, line spaces, and text fonts are prescribed; please do not alter them. You may note peculiarities. For example, the head margin in this template measures proportionately more than is customary. This measurement and others are deliberate, using specifications that anticipate your paper as one part of the entire proceedings, and not as an independent document. Please do not revise any of the current designations.

\section{STRATEGIC DECISION OF THE SYSTEM}

The following four notations will be used

$$
\begin{aligned}
& A=\left[\begin{array}{ccc}
-\left(P_{1}+Q_{1}+R_{1}\right) Y_{1} & X_{12} & -X_{13} \\
X_{21} & -\left(P_{2}+Q_{2}+R_{2}\right) Y_{2} & -X_{23} \\
-X_{31} & -X_{32} & -\left(P_{3}+Q_{3}+R_{3}\right) Y_{3}
\end{array}\right], \\
& A_{a}=\left[\begin{array}{ccc}
P_{1}+Q_{1}+R_{1} & X_{12} & -X_{13} \\
P_{2}+Q_{2}+R_{2} & -\left(P_{2}+Q_{2}+R_{2}\right) Y_{2} & -X_{23} \\
P_{3}+Q_{3}+R_{3} & -X_{32} & -\left(P_{3}+Q_{3}+R_{3}\right) Y_{3}
\end{array}\right], \\
& A_{\mathrm{z}}=\left[\begin{array}{ccc}
-\left(P_{1}+Q_{1}+R_{1}\right) Y_{1} & P_{1}+Q_{1}+R_{1} & -X_{13} \\
X_{21} & P_{2}+Q_{2}+R_{2} & -X_{23} \\
-X_{31} & P_{3}+Q_{3}+R_{3} & -\left(P_{3}+Q_{3}+R_{3}\right) Y_{3}
\end{array}\right], \\
& A_{c}=\left[\begin{array}{ccc}
-\left(P_{1}+Q_{1}+R_{1}\right) Y_{1} & X_{12} & P_{1}+Q_{1}+R_{1} \\
X_{21} & -\left(P_{2}+Q_{2}+R_{2}\right) Y_{2} & P_{2}+Q_{2}+R_{2} \\
-X_{31} & -X_{32} & P_{3}+Q_{3}+R_{3}
\end{array}\right] .
\end{aligned}
$$

Suppose there are two competing states between the three categories of cites, which are weak state of competition and strong state of competition. Weak state means that the competitive rates of corporate development (including selfdevelopment rate and the rate of development of competition) is higher than the loss of market share of competition. On the contrary, strong state can be defined.

After the analysis of the mathematical model using the equilibrium solution theory of differential equations, the appropriate strategies for the selected cites are given as follows.

(1) For $\left(P_{1}+Q_{1}+R_{1}\right) Y_{3}>X_{13},\left(P_{2}+Q_{2}+R_{2}\right) Y_{3}>X_{23}$ i.e. site 1,2 and 3 are in the weak state of competition with each other. The selected site 1 and site 2 must increase $X_{31}$ and $X_{32}$ to win the war. The right strategies would be $\operatorname{det} A_{c}<0$ and $\left(P_{3}+Q_{3}+R_{3}\right) Y_{1} \neq X_{31},\left(P_{3}+Q_{3}+R_{3}\right) Y_{2} \neq X_{32}$.

(2) For $\left(P_{1}+Q_{1}+R_{1}\right) Y_{3}>X_{13}$ and $\left(P_{2}+Q_{2}+R_{2}\right) Y_{3}<X_{23}$ i.e. site 1 and 3 are in the weak state of competition, and site 2 and 3 are in the strong state. One of the following conditions is required.

1) $\left(P_{3}+Q_{3}+R_{3}\right) Y_{1}<X_{31},\left(P_{3}+Q_{3}+R_{3}\right) Y_{2} \neq X_{32}$;

2) $\left(P_{3}+Q_{3}+R_{3}\right) Y_{1}>X_{31},\left(P_{3}+Q_{3}+R_{3}\right) Y_{2}<X_{32} \quad$ and $\operatorname{det} A_{b}>0$;

3) $\left(P_{3}+Q_{3}+R_{3}\right) Y_{1}>X_{31},\left(P_{3}+Q_{3}+R_{3}\right) Y_{2}>X_{32}$, $\operatorname{det} A_{b}>0$ and $\operatorname{det} A_{c}<0$.

(3) For $\left(P_{1}+Q_{1}+R_{1}\right) Y_{3}<X_{13},\left(P_{2}+Q_{2}+R_{2}\right) Y_{3}>X_{23}$, that is

1) $\left(P_{3}+Q_{3}+R_{3}\right) Y_{1}<X_{31},\left(P_{3}+Q_{3}+R_{3}\right) Y_{2}<X_{32}$;

2) $\left(P_{3}+Q_{3}+R_{3}\right) Y_{1}>X_{31},\left(P_{3}+Q_{3}+R_{3}\right) Y_{2}<X_{32}$;

3) $\left(P_{3}+Q_{3}+R_{3}\right) Y_{1}<X_{31},\left(P_{3}+Q_{3}+R_{3}\right) Y_{2}>X_{32} \quad$ and $\operatorname{det} A_{a}>0$;

4) $\left(P_{3}+Q_{3}+R_{3}\right) Y_{1}>X_{31},\left(P_{3}+Q_{3}+R_{3}\right) Y_{2}>X_{32}$, $\operatorname{det} A_{a}>0$ and $\operatorname{det} A_{c}<0$.

(4) For $\left(P_{1}+Q_{1}+R_{1}\right) Y_{3}<X_{13},\left(P_{2}+Q_{2}+R_{2}\right) Y_{3}<X_{23}$, the site 1 and site 2 still have the opportunity to win the war. If $\operatorname{det} A_{c}<0, F_{3}(0)<-\operatorname{det} A_{c} / \operatorname{det} A, F_{1}^{\prime}(0) \geq 0, F_{2}^{\prime}(0) \geq 0$ and $F_{3}^{\prime}(0) \leq 0$, the two small sites 1 and 2 will win, the powerful site 3 will be extinct.

(5)There are some other cases, which are worth pointing out:

1)For $\quad\left(P_{1}+Q_{1}+R_{1}\right) Y_{3}<X_{13} \quad, \quad\left(P_{2}+Q_{2}+R_{2}\right) Y_{3}<X_{23} \quad$, det $A_{c}>0$, the powerful site 3 will win, the two small sites 1 and 2 will be extinct;

2)For $\left(P_{1}+Q_{1}+R_{1}\right) Y_{3}<X_{13} \quad, \quad\left(P_{2}+Q_{2}+R_{2}\right) Y_{3}<X_{23} \quad$, $\operatorname{det} A_{c}<0, F_{3}(0)>-\operatorname{det} A_{c} / \operatorname{det} A, F_{1}^{\prime}(0) \leq 0, F_{2}^{\prime}(0) \leq 0$ and $F_{3}^{\prime}(0) \geq 0$, the powerful site 3 will win, the two small sites 1 and 2 will be extinct;

3)For $\operatorname{det} A<0, \operatorname{det} A_{a}, \operatorname{det} A_{b}, \operatorname{det} A_{c}>0$, the sites $1,2,3$ will coexist; 
4)For $\operatorname{det} A_{\mathrm{z}}<0, \operatorname{det} A_{c}>0$ and $\left(P_{1}+Q_{1}+R_{1}\right) Y_{3}<X_{13}$, the sites 1 and 3 will coexist, the site 2 will be extinct;

5)For $\operatorname{det} A_{a}<0$, $\operatorname{det} A_{c}>0$ and $\left(P_{2}+Q_{2}+R_{2}\right) Y_{3}>X_{23}$, the sites 2 and 3 will coexist, the site 1 will be extinct.

\section{A. Remark}

Based on the other cases 1) and 2), strong competitive state is useless disadvantaged for site 1 and 2. They should try to reduce $X_{13}$ and $X_{23}$, and try to improve $X_{31}, X_{32}, X_{12}$ and $X_{21}$. This is the reason of assumption (1) in 2.A.

\section{B. Example}

Now we turn back to the Weibo, and then the example will be given. Based on the market survey date, the parameters of the mathematic model can be taken as $X_{23}=0.13, P_{2}=0.05, Q_{2}=0.08, R_{2}=0.03, P_{3}=0.14$, $Q_{3}=0.12, R_{3}=0.05,1 / Y_{2}=0.55,1 / Y_{3}=0.90$.

Case 1: If choosing the strategy as $P_{1}=0.09, Q_{1}=0.12$, $R_{1}=0.03, X_{12}=0.11, X_{21}=0.13, X_{13}=0.03, X_{31}=0.11$, $X_{32}=0.04$ and $1 / Y_{1}=0.52$, the selected company will be extinct, i.e. The case 1 is not the appropriate strategy because of $\left(P_{1}+Q_{1}+R_{1}\right) Y_{3}>X_{13},\left(P_{2}+Q_{2}\right) Y_{3}>X_{23}$ but det $A_{c}>0$.

Case 2: If choosing the strategy as $P_{1}=0.11, Q_{1}=0.14$, $R_{1}=0.03, X_{12}=0.24, X_{21}=0.28, X_{13}=0.03, X_{31}=0.43$, $X_{32}=0.25$ and $1 / Y_{1}=0.85$. It means that we should raise the competition rate $X_{31}$ and $X_{32}$ such that $\operatorname{det} A_{c}<0$, $\left(P_{1}+Q_{1}+R_{1}\right) Y_{3}>X_{13}$ and $\left(P_{2}+Q_{2}+R_{2}\right) Y_{3}>X_{23}$. Note that $\left(P_{3}+Q_{3}+R_{3}\right) Y_{1} \neq X_{31}$ and $\left(P_{3}+Q_{3}+R_{3}\right) Y_{2} \neq X_{32}$, then the selected company will win the war, i.e. the case 2 is the appropriate strategy.

\section{CONCLUSIONS}

In this paper, the appropriate strategies have been stated for the selected site 1 to win the war in the coopetition environment of Internet Web searching market. In this process, the key method is the mathematic model with equilibrium solution theory of differential equations. After researching market share and the rate of self-development, the selected hot issue (site 1) can win the war under the appropriate complete strategic classification-- selecting appropriate parameters $P_{1}, Q_{1}, R_{1}$ and $X_{i j}$ for $\mathrm{i}, \mathrm{j}=1,2,3$. It is possible to extend the results to the other categories of companies in the coopetition market. I plan to study it in follow-up work a near future.

\section{ACKNOWLEDGMENT}

This work is supported by Anhui College provincial project of Natural Science Research (KJ2012B076).

\section{REFERENCES}

[1] Lai Linda S.L. and To Waiming. The emergence of China in the internet market, IT Professional. 2012, 14, 1, pp6-9. Article number: 6136216.

[2] CNNIC. The 30th statistics report on the internet development in China (in Chinese), 2012.

[3] Shaoyong Chen, Huanming Zhang, Min Lin and Shuanghuan Lv. Comparision of microblogging service between Sina Weibo and twitter, Proceedings of 2011 International Conference on Computer Science and Network Technology, ICCSNT 2011, v4, pp2259-2263.

[4] Louis Yu and Valerie King. The evolution of friendships in Chinese online social networks, Int. J. of Social Computing and CyberPhysical Systems, 2011, 1, pp180-205.

[5] Louis Yu, Sitaram Asur and Bernardo A. Huberman. What trends in Chinese social media, in Proceeding of the 5th ACM workshop on Social Network Mining and Analysis (SNAKDD2011), 2011. (also see arXiv: 11073522).

[6] Louis Yu, Sitaram Asur, Bernardo A. Huberman. Artificial Inflation: The True Story of Trends in Sina Weibo, 2012,arxiv: 1202.0327.

[7] Ming Wu, Jun Guo, Chuang Zhang and Jianjun Xie. Social media communication model research bases on Sina-weibo, Advances in Intelligent and Soft Computing, 2011, 123, pp445-454.

[8] Yuanshi Wang, Hong Wu. Dynamics of a cooperation-competition model for the WWW market, Physica A, 2004, 339, pp609-620.

[9] Jifa Jiang, Zhixin Cheng. The complete strategic classification for a cooperation-competition model in the WWW market, Physica A, 2006, 363, pp527-536.

[10] Xiaoji Wan, Guishi Deng, yang Bai and Shaowei Xue. The influence of learning and updating speed on the growth of commercial websites, Physica A, 2012, 391, pp4018-4030.

[11] Yawei Ren, Deli Yang, Xinjun Diao. Market segmentation strategy in internet market, Physica A, 2010, 389, 1688-1698. 